\title{
Anti-inflammatory Properties of a Fatty Acids Sugarcane Wax Oil Mixture on Models of
} Psoriasis and Allergy.

Rodríguez S.*, Ancheta O.*, Valdés T.*, Ledón N.**, Casacó A**. and Tolón Z.***.

* Electron Microscopy Laboratory, Biotechnology; National Center for Scientific Research. P.O. Box 6414, Havana, Cuba.

** Molecular Immunology Center, Havana, Cuba.

*** Chemistry Department, National Center for Scientific Research, Havana, Cuba.

Fatty acids have a wide range of biological roles and cellular functions, such as anti-inflammatory effects $[1,2]$. A mixture of fatty acids (FAM) from Sugarcane (Saccharum officinarum L.) wax oil, mainly composed of palmitic, oleic, linoleic and linolenic acids, exerts anti-inflammatory action in some in vivo and in vitro experimental models [Ledón N., Planta Medica, in press].

In this work, the effect of FAM on three animal models of cutaneous inflammation (mouse tail test for psoriasis and the allergy models of ear swelling response to ovoalbumin (mediated by CD4+Th 2 cells) and oxazolone- induced contact hypersensitivity in mice ear (related to CD4+Th 1 cells) has been studied by Transmission Electron Microscopy. Small fragments of skin tails and ears samples were fixed, dehydrated and embedded in Spurr resin [3].

\section{Mouse tail test for psoriasis.}

The induction of a granular layer by topically administered FAM in previously parakeratotic scale regions in the mouse tail was studied. In non-treated control group, lack of granular layer in the epidermal stratum was noted, as occurs normally in scale regions of adult mouse tail (Fig. 1A). FAM induced a significant and dose-dependent increase in orthokeratosis in the mouse tail epidermis; granular cells with prominent nucleus and typical keratohyalin granules in the cytoplasm were observed (Fig. 1B).

\section{Models of allergy.}

Clear symptoms of exocytosis in the dermis were observed after a treatment with ovoalbumin and oxazolone. In mast cells, intracellular spaces between granules and loss of cell integrity were found. In addition, collagen fibers packages disposition was not close around the cells (Fig. 2A, 3A). In both cases, FAM induced recovery of mast cell integrity and no signs of degranulation were noted; collagen fibers bundles organisation was close (Fig. 2B, 3B). This morphological changes induced by FAM are similar to those induced by triamcinolone in the same conditions.

\section{References:}

[1] H. Okuyama et al., Prog. Lipid Res. 35 (1997): 409.

[2] V. A. Ziboh, Lipids 31 (1996): S 249.

[3]O. Ancheta et al., Biotecnol. Apl. 13 (1996): 195. 


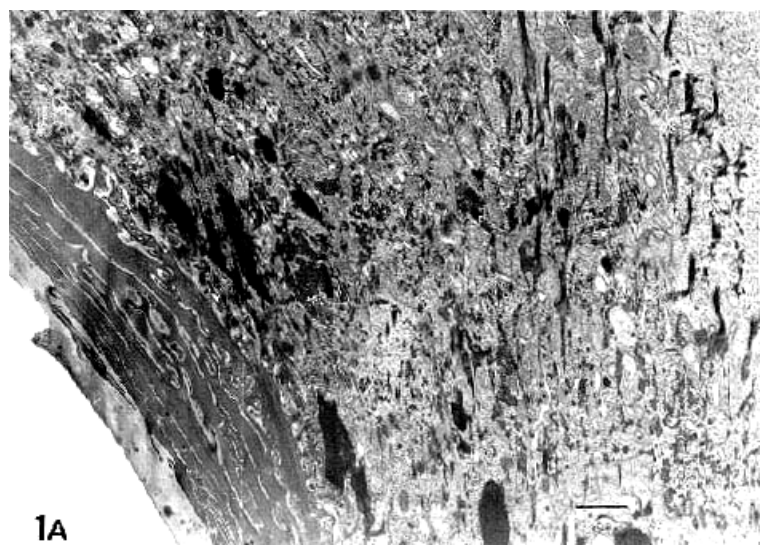

Interfollicular region of control group tail skin. Note lack of granular layer in the epidermal stratum. Bar, $1 \mu \mathrm{m}$.

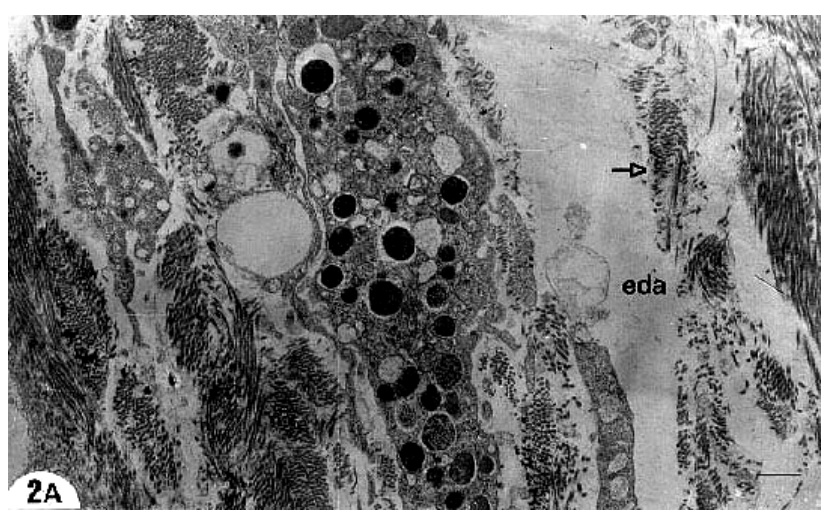

Ear dermis ultrastructure after a treatment with albumin. Spaces around mast cell granules (g); edematous dermal areas (eda) and separated disposition of collagen fibers packages

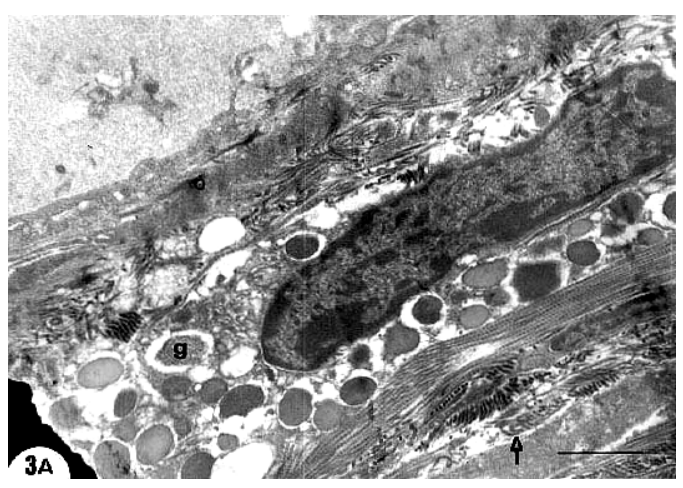

Effect of oxazolone in ear dermis. Observe intracellular spaces between granules $(\mathrm{g})$ in a mast cell. Collagen fibers packages (arrow) are not so close in the tissue. Bar, $1 \mu \mathrm{m}$.

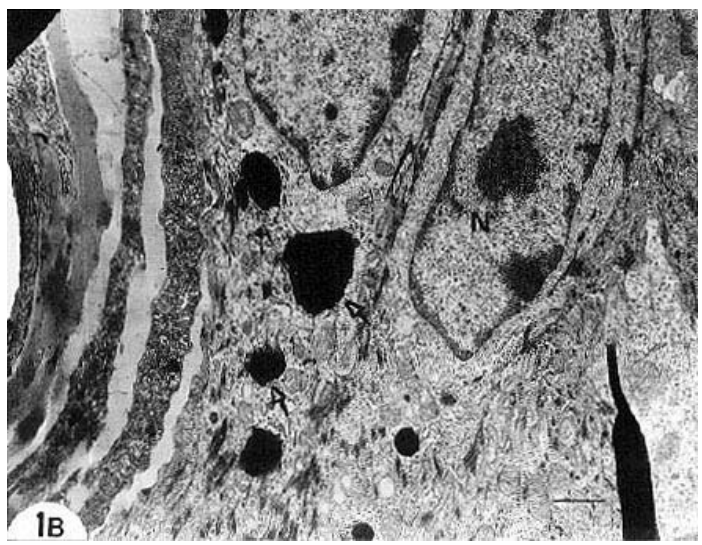

Interfollicular region of tail skin from fatty acids mixture treated group. Nucleus (N) and granules of keratohyalin (across) in granular cells are shown. Bar, $1 \mu \mathrm{m}$.

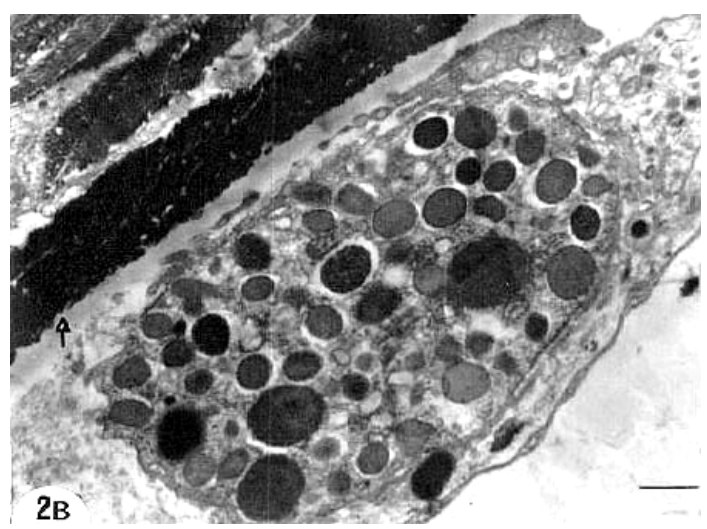

Effect of fatty acids mixture in albumintreated dermis. Note preservation of tissue morphology and mast cell integrity. Collagen fibers bundles (arrow) are close. Bar, $1 \mu \mathrm{m}$.

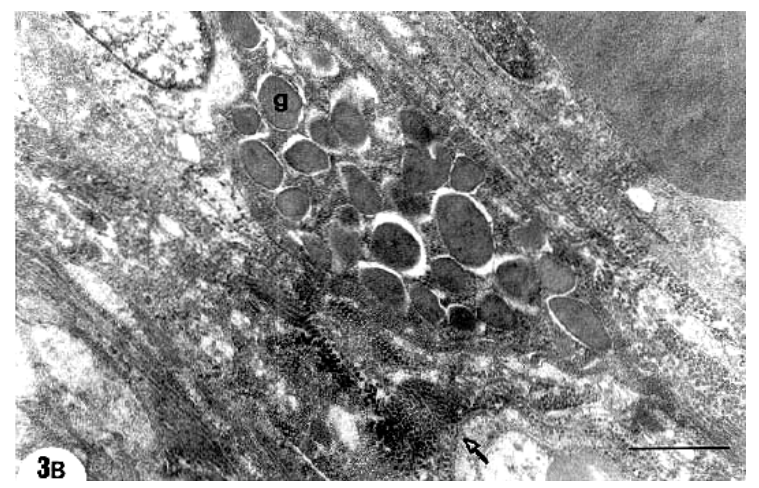

Fatty acids mixture effect in the dermis after allergy induced by oxazolone. Normal mast cell with numerous granules (g) is shown. Observe close organization of collagen fibers bundles (f). Bar, $1 \mu \mathrm{m}$. 